\title{
Family Vector Control Response Kit: Equipping Households to Prevent Amplification of Aedes- transmitted Diseases
}

John H. Thomas

Phoenix Ordinary LLC

Nfornuh Alenwi

The MENTOR Initiative

Andrew Trevett

UNICEF

\section{Eric Ochomo}

Kenya Medical Research Institute

Timothy Grieve

UNICEF

Richard Allan ( $\square$ richard.allan@mentor-initiative.net )

The MENTOR Initiative

\section{Research}

Keywords: Aedes aegypti, households, humanitarian, kits, mosquito, pictograms, practices, UNICEF, vector control

Posted Date: September 13th, 2021

DOl: https://doi.org/10.21203/rs.3.rs-713859/v1

License: (9) This work is licensed under a Creative Commons Attribution 4.0 International License. Read Full License 


\section{Abstract}

\section{BACKGROUND}

Natural disasters, such as earthquakes, hurricanes, and floods create ideal mosquito breeding conditions while simultaneously disrupting government services that prevent outbreaks where Aedes-transmitted diseases, and possibly other vector-borne diseases (VBD), are circulating. UNICEF, the MENTOR Initiative, and Kenya Medical Research Institute (KEMRI) evaluated novel UNICEF Family Vector Control Response Kits distributed to households $(\mathrm{HH})$ in Wajir Town, Northeast (NE) Kenya at the end of the rainy season (January/February 2019). This region regularly experiences epidemics of VBD during, and for several months after, rainy seasons. The premise behind this study was to determine if HHs can adopt the use of the kit contents based solely on pictures rather than needing a comprehensive education campaign. This was necessary for the following two reasons: 1 . Successful disruption of a disease outbreak often requires transmission be stopped at the $\mathrm{HH}$ level as soon as possible, 2. In the beginning of most largescale rapid response emergencies, it is challenging to enact and align comprehensive education campaigns with delivery of supplies. To stop transmission early, it is often faster, in UNICEF's experience, to deliver supplies directly to $\mathrm{HHs}$, especially if the global/regional/national supplies are strategically prepositioned in warehouses. The study aimed to determine key outcomes when HHs were given simple picture-based application instructions, without any other education, for different combinations of evidence-based insecticidal products, including adulticides, spatial repellents, larvicides, insecticidal window curtains, and personal protection. The products were those commonly expected to be found in retail markets or will become available through public health procurement channels.

\section{METHODS}

Six different vector control kit configurations were distributed to six randomly selected groups each of 60 $\mathrm{HH}$ in Wajir Town. The number of HH successfully used for data collection totalled 324, comprising 60 $\mathrm{HH}(19 \%)$ for direct observation to document behaviors as the kits were opened and contents were being used, and $264 \mathrm{HH}(81 \%)$ for interviews after using the kit contents. MENTOR measured the uptake, proper application, ability to follow pictorial directions for use, and acceptability at household level.

\section{RESULTS}

Each kit contained a booklet of pictogram Directions for Use (DFU) that described how the product was to be put to practical use, safety precautions, and specific directions where the products should be applied for best performance against Aedes mosquitoes. No further explanation or education was provided. Most interview respondents indicated positively they understood the pictograms for each product. This was an important outcome, given the low literacy level of the responders. The results of the research study provide an operational evidence-base as to the effectiveness of $\mathrm{HH}$ managing their own control practices using these kits in a highly insecure and challenging operational setting.

\section{CONCLUSIONS}


This is the first such study of its kind and has particular relevance adding a new approach to the emergency response capacity for disease control across similar operational settings. The results of the study are relevant wherever there is potential for disease outbreaks caused by Aedes sp and other mosquito vectors in emergency situations.

\section{Background}

The Zika virus outbreak that reached global attention in 2016 caught the World Health Organization (WHO), UNICEF, governments and aid agencies unprepared. The spread of the disease was exacerbated with the onset of natural disasters that impacted mosquito aquatic habitats, population densities, and human population movements. In San Juan, Puerto Rico densities of Aedes aegypti and Culex spp., vectors implicated in transmission of Zika and other arboviral diseases, sharply increased following Hurricanes Irma and Maria in 2017¹. A major earthquake (M7.8) in Ecuador in 2016 was thought to have affected climate conduciveness for increased mosquito breeding that led to an upsurge in Zika infections $^{2}$. Strong evidence was collected (2005-2009) showing that heavy rainfall and flooding in Dhaka, Bangladesh were coincident with increased availability of Aedes sp breeding sites and an increase in hospital admissions for dengue fever (spread by the same mosquitoes that transmit Zika virus $)^{3}$.

With over 24 countries reporting active transmission of the Zika virus in 2017, the US Centers for Disease Control (CDC) cautioned that the virus would continue to spread. Because no vaccine existed for the Zika virus, the $\mathrm{CDC}$ promoted that the primary means of preventing infections was to control the mosquito vector, Ae aegypti, and urged all persons in areas of active virus transmission especially pregnant women, to take active steps to avoid mosquito bites ${ }^{4}$.

Because UNICEF has a primary role in response to most natural disasters and widespread disease outbreaks, the Water, Sanitation, and Hygiene (WASH) Emergencies section of UNICEF commissioned a review of independent evidence supporting vector control activities in order to inform a decision and strategy for involvement by the organization in vector control activities ${ }^{5}$. The review clarified the characteristics and biology of Aedes sp. for not only transmission of Zika but also Dengue, Chikungunya, Yellow Fever, and Rift Valley Fever. Biology and behaviour of malaria Anopheline vectors and Culicine vectors of West Nile Virus were also noted to be relevant when natural disasters occur.

Major challenges combatting VBD in most affected countries include weak or lack of health system preparedness and emergency response, lack or inadequacies in early detection and diagnostics, lack of surveillance indicators and benchmarks, lack of case tracing and tracking and lack of effective risk communication and reporting tools. However, it is noteworthy that different vector control measures have promising levels of effectiveness in reducing mosquito densities and prevalence, even if not confirmed to break transmission or reduce infectious disease impact on communities ${ }^{6}$. 
The concept of integrated intervention for disease prevention, or integrated vector management (IVM), is gaining increasingly broader acceptance, although to date, consensus is still to be reached regarding the details of how and what combination of approaches can be most effectively implemented to manage disease ${ }^{7}$. Best practices in vector control must be defined for each setting (i.e. which tools or methods the community should employ), as well as what constitutes adequate or sufficient coverage in order to impact the vector population and virus transmission. Different responses will also have different outcomes depending whether applied in an urban or rural setting or a natural disaster or refugee crisis situation. Horstick and Runge-Ranzinger ${ }^{8}$ found that: (1) vector control could be effective, but implementation and coverage remained an issue; (2) single interventions were probably not useful; (3) combinations of interventions had mixed results; and (4) careful implementation of vector control measures may be most important. While the concept of vector control is reasonable, control must be early in an outbreak or strategically applied during inter-epidemic periods to prevent escalation in transmission. Community participation improved all interventions employed associated with it and so it is an indispensable component in any control programme ${ }^{9}$.

A key factor about vectors transmitting diseases is they are often found within and in close proximity to houses. Prevention measures, especially against Ae aegypti, are focused on that environment. Numerous control practices against eggs, larvae, and adults are supported by WHO recommendations ${ }^{10,11}$. Individual components such as strong community engagement in elimination of larval habitats ${ }^{12}$, larvicidal treatment of water holding containers, adult control using coils, consumer aerosol insecticides, spatial repellents, and insecticide treated curtains have been shown to have benefit in reducing indoor mosquito populations ${ }^{13-16}$. However, there remains a vital need for robust, rigorously designed field trials, with epidemiological and entomological outcomes, to improve the understanding of optimal implementation of existing tools and measure reduction in VBD transmission. Only then can strategyspecific programmes be realistically developed and evaluated ${ }^{7}$.

Based on this background a strategy was developed that would capitalize on the strengths of UNICEF with regards to engagement in humanitarian and emergency situations in resource-limited settings, maintenance of a visible presence in communities, government advocacy, and operation of an unrivalled global supply capability. A component of the strategy was to improve the speed of response when an Aedes-borne disease was first confirmed or highly suspected. Built on UNICEF's experience with other disease management it was thought that if the infected person could be isolated as infection loci then further transmission might be delayed or prevented for a short period ${ }^{49}$. That action would give a window of time for more formal, widespread governmental vector control activities to be initiated, thus preventing or reducing the chance of the localized outbreak from becoming epidemic ${ }^{50}$. In order to isolate the infected person from mosquito exposure the concept of a Family Vector Control Response Kit was devised. The kits would be supplied by UNICEF or other aid organizations and distributed by health centre workers to all $\mathrm{HH}$ in camps or villages where infected persons reside or that have the potential for transmission. The kits would contain commonly available consumer insecticidal products for 1) targeted controlling or repelling adults and treating hiding places, 2) preventing entry of mosquito adults into 
those houses, 3) stopping emergence of new individuals from water containers within the houses where infected persons lived, and 4) repellent for personal protection. The kit contents would be used by members of the $\mathrm{HH}$ and would afford immediate mosquito control without delay that might occur waiting for other actions in the community.

Useful consumer products that could be included in the kits are available in most countries (aerosol insecticides, coils, spatial repellents, hand-trigger sprayers, curtains, larvicides, and repellent lotions). Typically these products are supported by efficacy data and are registered by national regulatory authorities. However, labelling that gives specific directions how safely to use and where to apply the products in the house to control vector mosquitoes are complex or unclear for the typical resident in settings where outbreaks might occur. Challenges correctly interpreting and following label use instructions can become even more acute in populations with low levels of formal education and low literacy rates. It is documented that even farm workers who apply pesticides on a regular basis do not have full comprehension of label instructions for use and safety ${ }^{17,18}$. However, the United Nations produced the Globally Harmonized System of Classification and Labelling of Chemicals (GHS) ${ }^{19}$ that includes a series of pictograms that could be used by manufacturers to provide guidance on safety and handling of their products. With the expectation that use directions needed to be universally understandable, and with prospects that users may be limited in translation or reading ability, consideration was given to providing kits with pictogram directions for use (DFU) for each of the products. The pictograms would reinforce applications that targeted adult mosquito resting and hiding places, coverage, timing, and precautions. The graphics would also reinforce proper treatment of water containers that could not be easily emptied.

The main objective of this study was to determine if participants in a rural setting, that was similar to the environment of a humanitarian calamity or natural disaster, could follow pictogram use directions for each of the products included in Family Vector Control Response Kits. The kits were configured with different product types commonly found in supermarkets. Preferences and ease of understanding the targeted applications were measured between technologies.

\section{Methods}

\section{Study Site}

A group comparison study was conducted to evaluate $\mathrm{HH}$ acceptance and usage of six different combinations (kits) of vector control products.

This study was conducted in Wajir town, which is the capital and largest city in Wajir County in NE Kenya (Fig. 1). It sits at a latitude and longitude of $01^{\circ} 45^{\prime} 00^{\prime \prime} \mathrm{N} 40^{\circ} 03^{\prime} 00^{\prime \prime} \mathrm{E}$. Wajir shares its borders with Somalia to the east and Ethiopia to the North. It is part of territory carved out of Somalia during colonial times and as such, the population is $90 \%$ ethnic Somali. In 2019 the town had a population of $90,116^{20}$. Wajir is located in an arid area prone to drought ${ }^{48}$. The county is also prone to seasonal flooding during its two 
rainy seasons; the 'short' rains experienced between October to December and the 'long' rains from March to May each year. This is a highly seasonal epidemic zone, with low transmission of malaria, rift valley fever, lymphatic filariasis, dengue or other diseases outside of the rainy season ${ }^{21}$. This means that all age groups are susceptible to the diseases transmitted by the bite of infective Aedes, Anopheles, and Culex mosquitoes. The population of interest included all occupants of enrolled $\mathrm{HH}$ comprising children and adults of all ages.

Wajir town is made up of 10 distinguishable neighborhoods. From these 10 areas, seven were randomly selected, based on the ecological, economical activities, educational level and reasonably uniform house structures and environmental conditions. These seven areas formed the treatment groups, or arms, for this study. All the villages (manyattas) within each of the seven treatment groups were evaluated for suitability. Out of these, two villages from within each group were randomly selected for the study to make up the targeted number of $\mathrm{HH}$ per treatment.

A total of $390 \mathrm{HH}$ were mapped and randomly assigned to seven arms. Mapping was done using tablets for data collection, and GPS coordinates were entered into an electronic data collection tool (supplied by KEMRI). Each treatment arm had $60 \mathrm{HH}$ and the control arm had $30 \mathrm{HH}$. On average, there were 8 persons per $\mathrm{HH}$ for a total of 3,120 persons impacted by the study.

Coordination meetings were held with the County Director of Health and the Director of Public Health in Wajir to plan for the study as well as to select workers for $\mathrm{HH}$ mapping, distributing kits, and conducting post distribution observations/interviews. The workers were either public health officers or graduate students. These study survey team members were trained on interview techniques and methods to conduct observational studies. Observational and interview questionnaires were discussed at length and minor amendments were made. This exercise helped make the questionnaires easy to understand/implement and relevant for the local context. A second day of training was spent in the field practicing various techniques that were taught during the theoretical part of the training.

After kits were distributed to all households, a team of 2 monitors performed close observations of 10 households in each research arm to better understand if use directions were being followed. They spent a full day observing each household from kit receipt until each product package had been opened and attempts had been made to use every product in the kit. A second team of 2 monitors visited the remaining $50 \mathrm{HH}$ in a treatment arm a few days after the $\mathrm{HH}$ had received, opened and used the products. A standardized follow-up questionnaire was used to query if people in the HH could explain and demonstrate the use of the components and give impressions of the kit concept. Data was tabulated by MENTOR staff.

\section{Test Design}

The treatment arms consisted of 6 different kit configurations based upon the inclusion or exclusion of long-lasting insecticidal curtains (LLIC). The purpose of the curtains was to prevent entry of new adults after adult mosquito control treatments were applied to eliminate resident vectors. The mosquito adult 
control tools included mosquito coils, aerosol insecticide sprays, and slow-release passive repellent emanators (referred to as spatial repellent in this study) ${ }^{22}$. Kits for all arms included a trigger hand pump bottle of insecticide for targeted application to hiding places, a bottle of larvicidal film, a fly swatter for mechanical control of stray mosquitoes that might be flying around in the house, and a bottle of personal repellent. Kit products were assembled and packaged into paper bags in six different combinations, together with pictograms for each of the kit components (for example see Fig. 2).

Kit configurations for each arm are shown below:

- Arm 1: Spatial repellent + LLIC + trigger sprayer, larvicidal film, fly swatter, \& personal repellent

- Arm 2: Spatial repellent + trigger sprayer, larvicidal film, fly swatter, \& personal repellent

- Arm 3: Aerosol spray can + LLIC + trigger sprayer, larvicidal film, fly swatter, \& personal repellent

- Arm 4: Aerosol spray can + trigger sprayer, larvicidal film, fly swatter, \& personal repellent

- Arm 5: Mosquito coil (x 4) + LLIC + trigger sprayer, larvicidal film, fly swatter, \& personal repellent

- Arm 6: Mosquito coil (x 4) + trigger sprayer, larvicidal film, fly swatter, \& personal repellent

- Arm 7: no kits (untreated control)

\section{Product Descriptions}

\section{Spatial Repellent}

This is an emanator that passively releases the active ingredient, transfluthrin (1.0\%), a WHO-approved volatile pyrethroid repellent. It is manufactured by S.C. Johnson \& Son (SCJ). While not yet registered in Kenya, the spatial repellent product included in this study was shown to be effective against both vectors and disease incidence in other testing. A 2017 laboratory and semi-field test involving female Aedes mosquitos saw a $96 \%$ reduction in blood feeding success. When hung near entry points, the emanator reduced mosquito entry by $88 \%{ }^{23}$. A 2018 study found that eave ribbons treated with the spatial repellent transfluthrin effectively protected against indoor-biting and outdoor-biting Anopheles mosquitoes ${ }^{24}$. A 2019 cluster randomized placebo control trial conducted in Sumba, Indonesia with the spatial repellent showed a significant impact on malaria infection (about $60 \%$ protective efficacy) among the highest-risk clusters $^{25}$. More recently another randomized control trial provided conclusive evidence of the protective efficacy of transfluthrin based spatial repellents against Aedes vectors of arboviral diseases ${ }^{51}$.

\section{Mosquito Coil}

The mosquito coil used in this study had d-allethrin (0.2\%) as active ingredient (Kenya Reg. No. PCPB(CR)0972), brand name KAPI FLOWER® Mosquito Coil, manufactured by KAPI Ltd., Kenya. A systematic review of mosquito coils and passive emanators concluded they provide a deterrence effect (prevent entry of mosquitoes) of $40-80 \%$, increase proportion of mosquitoes that exit earlier from huts burning coils compared to huts without coils, and confer protection against mosquito bites ${ }^{26}$. A 2013 study evaluated the bio-efficacy of five commonly used d-allethrin $(0.1-0.3 \%)$ based coils on non-blood 
fed female adult An gambiae mosquitos. It found that mortality ranged from $36 \%-72 \%$ with KT50 and $34.92 \%$ with KT9027.

\section{Aerosol Spray Can}

SUPAKILL ${ }^{\circledR}$ aerosol spray (Kenya Reg. No. PCPB(CR)0800) active ingredients include: pyrethrins (2.0\%) + cypermethrin (1.56\%) + tetramethrin (4.0\%) + piperonyl butoxide (5.0\%), manufactured by Pyrethrum Board of Kenya and registered by Sumitomo Corp. A simulated field study on the efficacy of commercial household aerosol insecticides was conducted in 2009 and found that the field efficacy of commercial household aerosols applied at their recommended dosages against Ae aegypti mosquitoes induced total mortality ${ }^{28}$. Another study of 13 commercially available aerosol insecticides showed that 3 of the products provided $100 \%$ control after 24 hours exposure but there was considerable variability in efficacy provided by other products ${ }^{29}$. The authors also concluded that location of mosquito cages in a room affected results. In another study comparing consumer aerosols for control of An gambiae in Kenya it was demonstrated that some products had rapid knockdown and mortality but products with the same brand name coming from another country did not provide similar speed of action ${ }^{30}$. It was also determined that indoor resting densities were not greatly reduced a few days after spraying. The authors concluded the spray did not suppress entry of mosquitoes from outside.

\section{Trigger Sprayer}

KAPI DUDU® spray (Kenya Reg. No. PCPB(CR)0848) active ingredients include: pyrethrins (0.1\%) + piperonyl butoxide (0.2\%), manufactured by Pyrethrum Board of Kenya and registered by KAPI Ltd. Piperonyl-Butoxide (PBO) is a synergist that increases the insecticidal activity of pyrethroids in areas with pyrethroid-resistant mosquitoes. While there was awareness of the increasing pyrethroid resistance in Kenya, the range of product choices for use in trigger sprayers was limited to those which are registered by the Pest Control Products Board (PSPB) and which are easily available in Kenya.

\section{Long-Lasting Insecticidal Curtains (LLIC)}

DawaPlus ${ }^{\circledR} 2.0$ (Kenya Reg. No. PCPB(CR)1321) active ingredient includes: deltamethrin 80 mg/sqm, manufactured by Tana Netting, a subsidiary of NRS Moon Netting FZE as an insecticidal net that can also be manufactured as curtains. The Thirteenth WHOPES working group paper measuring the efficacy of LLIC to kill and or inhibit blood-feeding of An gambiae found that mortality and knockdown was $100 \%$. Even after washing the curtains 20 times they remained effective with mortality at $96.6 \%$ and knockdown at $98.3 \%$. Furthermore, when tested in huts, the blood feeding rate in huts with LLIC was $4.8 \%$ as compared to control huts of $37.5 \%^{31}$. Tests in Zaire against Ae aegypti mosquitos also demonstrated the efficacy of deltamethrin-impregnated curtains with a $100 \%$ reduction in indoor biting ${ }^{32}$. In a study in Mexico LLIC were shown to reduce the indoor abundance of $A e$ aegypti in $\mathrm{HH}$ in rural but not in urban/suburban study sites ${ }^{33}$. In Cuba there was strong acceptance of LLIC initially but that enthusiasm waned over time because of lowered perceived efficacy. The HH expected to observe dead mosquitoes beneath the curtains in that trial ${ }^{34}$. 


\section{Larvicidal film (LF)}

A solution of $78 \%$ polydimethylsiloxane (silicone), brand Aquatain ${ }^{\circledR}$ AMF, was prequalified in 2018 by the World Health Organization (WHO) for public health use ${ }^{35}$, is exempt from EU Biocide regulations, and is registered in over 60 countries for use by $\mathrm{HH}$ or professionals. The manufacturer, Aquatain Products Pty Ltd, Australia, has received permits for import and testing by the Kenya Pest Control Products Board. This LF spreads across the surface of standing water, forming a very thin coating which lasts for at least 4 weeks. As the silicone polymer has a low surface tension, mosquito larvae and pupae cannot attach to the surface to breathe - causing them to drown ${ }^{36}$. A trial was conducted to evaluate the potential of LF as a mosquito control agent in a Kenyan rice irrigation scheme. An application at a dose of $2 \mathrm{ml} / \mathrm{m} 2$ on rice paddies showed early stage anopheline larvae numbers being reduced by $36 \%$, and late stage anopheline larvae by $16 \%$. However, even at lower doses of $1 \mathrm{ml} / \mathrm{m} 2$ there was a $93.2 \%$ reduction in the emergence of anopheline adults and $69.5 \%$ reduction in the emergence of culicine adults. Furthermore, no pupation was observed in treated buckets that were part of a field bio-assay carried out parallel to the trial. The LF had no negative effect on rice plants or on a variety of non-target organisms, except backswimmers ${ }^{37}$. In another test, a laboratory assessment was conducted to determine LF efficacy against Ae aegypti mosquitoes. At the recommended dosage $(1 \mathrm{~mL} / \mathrm{m} 2$ of water surface), mortality of pupae was $99 \%$. Gravid females also avoided laying eggs in LF-treated oviposition cups. There was no influence of physical factors on LF's efficacy and no toxic effects on fish and plants ${ }^{38}$.

\section{Personal Repellent}

Tabard® Lotion active ingredient is DEET (19.5\%), manufactured by Acorn Products Pty Ltd, South Africa. There are numerous studies over many years demonstrating the effectiveness of the active ingredient DEET. This formulated product was shown to be effective under laboratory and field conditions ${ }^{39}$. A 2002 study showed that topical application of insect repellent can inhibit mosquitos from biting ${ }^{40}$. A study on An arabiensis females showed that treating ankles and feet with a consumer brand of DEET repellent led to a greater than threefold reduction in biting ${ }^{41}$. Similarly, a 2004 paper evaluating the sensitivity of $A e$ aegypti and An gambiae mosquitoes to DEET found that Ae aegypti were highly sensitive to DEET based repellents ${ }^{42}$.

\section{Fly Swatter}

Mechanical device consisting of a piece of semi-rigid mesh connected to a handle. While there are no scientific studies on the efficacy of fly swatters as a vector control method, this inexpensive tool was included in the kit as an additional level of personal protection. The intent was to give users greater involvement in the control of vectors and hopefully increase the desirability of the kits.

\section{Results}

Household demographics 
Of the $360 \mathrm{HH}$ enrolled for the study, kits were effectively distributed to $350 \mathrm{HH}(97 \%)$. The number of $\mathrm{HH}$ successfully used for data collection totalled 324, comprising $60 \mathrm{HH}(19 \%)$ for direct observation to document behaviors as the kits were opened and contents were being used, and $264 \mathrm{HH}$ ( $81 \%$ ) for interviews after using the kit contents. Most of the responders were uneducated adult females who communicated mainly in the local Somali language. The interviews were conducted in either that dialect or in Swahili as possible. The participants indicated they understood the purpose of the kits they were given and the purpose of most of the components.

The remaining $\mathrm{HH}$ were not observed or interviewed for the following reasons: either $\mathrm{HH}$ was locked or the household head was absent $(n=11)$; the HH refused the product $(n=10)$; the kit was received but not used $(n=4)$, or the household head declined to be interviewed $(n=1)$.

The majority of the $\mathrm{HH}$ respondents were female $(71 \%, n=188)$, while $29 \%(n=76)$ were male. Most of the participants/responders were between ages $20-49$ years $62 \%(n=163)$ while $37 \%(n=97)$ were above 40 years of age. Regarding education, $61 \%$ of the respondents reported that they had never attended school, $17 \%$ had attended primary school, and $9 \%$ had attended post-secondary school or college. Overall, $97 \%$ of the response could speak Somali language, while $44 \%$ could speak Swahili and only $33 \%$ could speak the English language. Of the $264 \mathrm{HH}$ interviewed, 83\% (220) had another adult present in the $\mathrm{HH}$. Of the 220 adults, $38 \%$ had never attended school, $18 \%$ had attended primary school, $28 \%$ had attended secondary school, and $15 \%$ had attended post-secondary school.

\section{Participant understandings}

When asked if the purpose of the kits had been adequately explained and understood $97 \%$ of respondents confirmed they definitely or at least somewhat understood. When asked if they understood the purpose of each mosquito control product included in the kit there were also positive responses (Fig. 3).

Each kit contained a booklet of pictogram Directions for Use (DFU) that described how the product was to be put to practical use, safety precautions, and specific directions where the products should be applied for best performance against Aedes mosquitoes. Most interview respondents indicated positively they understood the pictograms for each product (Fig. 4). This was an important outcome given the educational level of the responders.

The interview responses were confirmed by direct observation of a subset of $\mathrm{HH}$ as they handled products in the kits (Table 1). Over $80 \%$ of those observed were able to follow the pictogram instructions for adult control products. The larvicidal film presented a challenge for some users (21\%). 
Table 1

Observed user ability to follow the pictogram Directions for Use (DFU) for each product in their kits.

\begin{tabular}{|llll|}
\hline & Followed DFU (\%) & Did not follow DFU (\%) & Did not use product (\%) \\
\hline Coil & 95 & 5 & 0 \\
\hline Aerosol & 95 & 5 & 0 \\
\hline Spatial repellent & 85 & 10 & 5 \\
\hline Trigger sprayer & 92 & 6 & 2 \\
\hline Curtains & 90 & 10 & 0 \\
\hline Personal repellent & 88 & 12 & 0 \\
\hline Larvicidal film & 71 & 21 & 9 \\
\hline Fly swatter & 89 & 11 & 0 \\
\hline
\end{tabular}

When asked why some of the products in the kits were not used the most common reason was they did not know how to use the product $(36 \%)$ or for what is was to be used $(28 \%)$. Other rationale for not using a product included they did not think it would be effective (14\%), did not know when it should be used $(11 \%)$, or thought it was unsafe $(7 \%)$.

Participants were asked to rank each product by difficulty to follow the DFU (Fig. 5). Coil pictograms were the easiest to follow and the larvicidal film was the most difficult. Further, when asked if the DFU pictograms explained how to use each product in a way that was easy to understand, most of the respondents stated that the DFUs were easy to understand.

When participants were asked about their knowledge of the time of the day each product was supposed to be used, as indicated in some of the pictograms, the average response was during morning hours and all were thought to be used before evening hours (Fig. 6). The majority of the respondents used the products in the bedroom. The exceptions were the larvicidal film, for which $83 \%$ of the respondents used the product outside the house, and the personal repellent that was applied to individuals rather than surfaces (Fig. 7).

When participants were asked to list the products from the most useful (1) to the least useful (6), the findings were analyzed in terms of the proportion of participants that listed the product within the first three rankings (1-3) as most useful, and within the last three rankings (4-6) as least useful. The trigger sprayer had the highest usefulness rating ( $90 \%$ of responders) followed by aerosol insecticide $(84 \%)$, larvicidal film (84\%), coils (75\%), and personal repellent (70\%). Responders rated less useful the interventions with which they were less familiar: insecticidal curtains (49\%), spatial repellent (34\%), and fly swatters $(30 \%)$. 
When asked about types already in the $\mathrm{HH}, 7 \%(\mathrm{n}=18)$ of respondents stated that they had products similar to the trigger sprayer (Dudu Spray) in their HH. Another 25\% $(n=22)$ of respondents stated that they had products similar to the aerosol spray (SUPAkill) in their HH. Mosquito coils and personal repellents were also identified as product types that could be found in $\mathrm{HH}$ ( $9 \%$ of respondents each). However, participants indicated they did not think those product types came with clear DFU (Fig. 8).

The participants were given the opportunity to suggest other control products that should be included in the kits. The list included insecticidal mosquito nets (74\% response), more aerosol insecticide (12\%), coils, candles, and emitters (6\%), treated mattresses and bedsheets (4\%), water treatment tablets or chlorine (3\%), and lemongrass oil (1\%). When asked to rate the overall value of the kit the response was favourable with $85 \%$ rating the Family Vector Control Response Kit as good to excellent (Fig. 9).

\section{Household (HH) knowledge and perception of vector control}

When respondents were asked if anyone in the household had ever been infected with an Aedestransmitted disease there was on average an $8 \%$ positive response. When pressed if it was dengue fever, chikungunya fever, yellow fever or Rift Valley fever; $12 \%(n=31)$ of the respondents confirmed that at least one person in their $\mathrm{HH}$ had been infected with either Rift Valley fever (3\%), yellow fever (9\%), dengue fever (6\%), or chikungunya fever (5\%).

On average, $89 \%$ of respondents did not know how diseases were spread by Aedes mosquitoes. Regarding respondents' knowledge of how dengue fever, chikungunya fever and yellow fever are transmitted, only $12 \%(31 / 264)$ of those respondents had correct knowledge of how dengue fever is transmitted, followed by correct knowledge about the transmission of chikungunya fever (9\%); yellow fever (9\%); and Rift Valley fever (15\%).

Regarding respondent's knowledge of mosquito breeding sites around the household, more than half (56\%) were not able to identify breeding sites. The other $44 \%$ (115/264) of respondents had correct knowledge of mosquito breeding sites around the house; stating that stagnant water, latrines, wells, water containers and bathrooms can act as breeding sites for mosquitoes.

\section{HH survey of mosquito control practices}

The respondents stated that mosquito control is regularly applied in the following areas of the house: adult bedroom 95\% (252/264), kitchen 84\% (223/264), living room 40\% (105/264), bathroom 23\% (60/264), children's bedroom $9 \%(25 / 264)$, and other areas $3 \%(2 / 264)$.

When asked how often mosquito control products were used, $51 \%$ of the respondents $(134 / 263)$ indicated daily or at least more than once per week. Others indicated they use only when mosquitoes are present $(35 \%)$ or only during the rainy season $(14 \%)$.

Most respondents (87\%) listed mosquito nets as the most common method of mosquito control (229/264). Other control methods included spraying (5\% of respondents), coils $(3 \%)$, or smoke, candle, 
and brush clearing (5\%). When asked about specific types of control over half the respondents had used smoke or candles (51\%) and a few (4\%) had experience with plug-in emitters.

More than half of the respondents indicated they purchase mosquito control products from either a kiosk $(52 \%)$ or a supermarket $(34 \%)$. Other places where such products were purchased included pharmacies, small stores, or from the street vendors. There is a clear indication from this brief survey of current practice that respondents were familiar with available mosquito control products.

\section{Discussion}

The complex setting in Wajir is representative of factors that affected disease risks and operational disease control challenges in many complex humanitarian emergency settings today. Innovative solutions are urgently needed to help fill the gaps in VBD protection for families that are otherwise put at great risk. Furthermore, effectiveness of the core existing vector control tools and strategies for VBD prevention, based on killing mosquitoes when they seek to bite people sleeping in their homes at night, such as long-lasting insecticidal nets (LLINs) and indoor residual spraying (IRS), is increasingly challenged by insecticide resistance. These tools are also unsuited to prevent Aedes-borne diseases because this mosquito bites during daytime, inside or outdoors, and often rests outside ${ }^{43,44}$.

This study represents the first of its kind to consider putting tools for vector control immediately in the hands of $\mathrm{HH}$ at initial alert of an outbreak. Evidence-based Family Vector Control Response Kits that can quickly be deployed and distributed, that are easy to use by $\mathrm{HH}$, and that are effective against mosquitos could potentially fill the gap in disease prevention when families are affected by conflict, natural disasters, or early stage epidemics, whilst awaiting larger scale and longer lasting disease control interventions. Despite the modest scope of the study it produced important results on the feasibility of Family Vector Control Response Kits being acceptable and usable by householders. The potential needs to be explored for reducing the risk of vector-borne disease transmission during gaps in response to natural disasters or humanitarian emergencies that include outbreaks of mosquito-transmitted diseases. The main objective of the Family Vector Control Response Kit user acceptance study was to determine if different combinations of vector control tools in the kits would be used appropriately and accepted by $\mathrm{HH}$ when given with only visual instructions. The products were those commonly found in retail markets. The graphic use directions (pictograms) were customized by MENTOR Initiative to demonstrate application techniques specific for control of Aedes mosquitoes, as opposed to the general instructions commonly found on labels, often in text that cannot be translated by users.

Participants did not have much awareness of key diseases spread by Aedes mosquitoes nor basic facts about biology and means by which transmission occurred. However, they did regularly engage in mosquito control in their houses. It is assumed this was mainly to control nuisance mosquitoes such as Culex spp. HH did rely upon mosquito nets as the most common method of control but also used consumer sprays, coils, and smoke. The products were purchased from kiosks, supermarkets, pharmacies, and small vendors ${ }^{52}$. This behaviour demonstrated a clear awareness of the risk or irritation 
caused by biting insects and the $\mathrm{HH}$ desire to reduce biting insects in their homes. It explained why the acceptance and the generally correct usage of the vector control household kits, and its different tools, was so high across all arms.

A principal finding of the study was the confirmation that the pictogram DFU for most of the product types were understood and followed by most participants. This is an important validation since these directions did not require translation or education to be understood by the users. The pictograms can also be used across a range of products for each product type thus expanding utility in most countries even as product availability varies.

Participants indicated the usefulness of different products in the kits varied in ranking. Some trend related to difficulty of following the respective DFU may have influenced the ranking. If that was the case, improvement in perceived usefulness may be possible with revised pictograms. Alternatively, kit contents should be revised and some components dropped if the value cannot be confirmed. However, when asked to rate the kits the majority of participants gave it a good to excellent value rating.

This study was not designed specifically to evaluate mosquito control by this integrated approach. That undertaking would require larger scale and attention to key environmental factors that affect increases in population densities ${ }^{45}$. Components supplied in family vector control response kits would have to be used correctly by $\mathrm{HH}$. It was expected that kit components would perform in agreement with previously published field tests and deliver a measureable level of control. The efficacy of individual kit components has been extensively evaluated or reviewed in other studies ${ }^{18,46,47}$. While each tool had positive results there were weaknesses also identified.

None of those studies combined adult knockdown aerosol with targeted surface spraying, prevention of re-entry with insecticidal curtains, and larval control applied by $\mathrm{HH}$ members with the intention of creating a mosquito-free environment combined with personal protection. This study represents the first attempt to provide a kit of vector control tools to $\mathrm{HH}$ for them to use prior to more formal action by the community or government. The focus of the trial was to document the ability to follow pictorial application instructions that are not usually included with products obtained from local markets. The theory is when products are appropriately applied the $\mathrm{HH}$ population of mosquitoes can be controlled or eliminated before further transmission occurs.

\section{Conclusions}

The present research validates that pictogram use directions can be understood and followed by users with low rates of literacy. There is no need for translations as carefully designed pictures allow for high rates of adoption for the intended use without need for a comprehensive educational campaign. This is a first step toward the goal of providing Family Vector Control Response Kits that can be rapidly deployed at first signs of outbreak and for use after natural disasters when normal supply chains and operations are disrupted. Further steps include confirming the efficacy of reducing indoor mosquito densities with 
positive impact on disease transmission, gaining global buy-in to using $\mathrm{HH}$ vector control kits for rapid large scale emergency response, evaluating kits in more countries, improving the picture diagrams, and refining key contents to most essential products.

As consumers grow more familiar with benefits of the kits, their perceptions of usefulness and ability to interpret the instructions are expected to increase. A comprehensive education campaign, conducted without the pressure of an immediate outbreak, could also improve adoption over time. This would fit with the premise that supplies will arrive before a more formal, comprehensive campaign gets moving. This is important because innovation in the space of rapid, household vector control should lead to userfriendly, less expensive interventions.

\section{Abbreviations}




\begin{tabular}{|ll|}
\hline ACAPS & Assessment Capabilities Project \\
\hline Ae & Aedes \\
\hline An & Anopheles \\
\hline CDC & US Centers for Disease Control \\
\hline DFU & Directions for Use \\
\hline GHS & Global Harmonized System of Classification and Labelling of Chemicals \\
\hline GPS & Global Positioning System \\
\hline HH & Household \\
\hline IRS & Indoor residual spray \\
\hline IVM & Integrated Vector Management \\
\hline KEMRI & Kenya Medical Research Institute \\
\hline LF & Larvicidal film \\
\hline LLIC & Long-lasting insecticidal curtains \\
\hline LLIN & Long-lasting insecticidal nets \\
\hline NE & Northeast \\
\hline PSPB & Pest Control products Board \\
\hline SCJ & S.C. Johnson \& Son \\
\hline UNECE & United nations Economic Commission for Europe \\
\hline VBD & Vector-borne disease \\
\hline WASH & Water, Sanitation, and Hygiene \\
\hline WHO & World Health Organization \\
\hline
\end{tabular}

\section{Declarations}

\section{Ethics approval and consent to participate}

Permission to carry out the study was obtained from the Kenya Medical Research Institute (KEMRI) Scientific and Ethics Review Unit, and from the Wajir County Department of Health. Planning and implementation of the study was conducted in close collaboration and coordination with the Wajir County Department of Health. The study population and community leaders in Wajir town were fully sensitised on the purpose of the study and the potential advantages, disadvantages, and risks it might entail. During the recruitment and selection of $\mathrm{HH}$, written consent was obtained from all the household heads or other adult representative for every household included in the study. 


\section{Consent for publication}

Not applicable

\section{Availability of data and materials}

The datasets generated and/or analysed during the current study are not publicly available because the study was undertaken in an area subject to ethnic conflict and the need to protect study participants identity and household locations, but are available from the corresponding author on reasonable request.

\section{Competing interests}

The authors declare that they have no competing interests.

\section{Funding}

This study was supported by funding from UNICEF through its WASH Emergencies unit.

\section{Author's contributions}

JT, RA, AT, and TG conceived the study and participated in fund procurement for this research. NA, EO, and AT participated in participant recruitment, field activities, and data acquisition. JT, RA, and NA contributed to drafting and revising the manuscript. All authors read and approved the final manuscript.

Corresponding authors

Correspondence to John Thomas (john.thomas@phnxord.com) or Richard Allan (richard.allan@mentorinitiative.net) .

\section{Acknowledgements}

Appreciation is extended to S.C. Johnson \& Son for making the spatial repellent emanator product available for use in this study.

\section{Author information}

Affiliations

Phoenix Ordinary LLC, 18 Young Way, Bridgewater, New Jersey US 08807

John H. Thomas

The MENTOR Initiative, Burns House, Harlands Road, Haywards Heath, UK RH16 1PG

Richard Allan, Nfornuh Alenwi

UNICEF, Rua N’Gola M'Bandi, Complexo INAC, Luanda, Angola 
Andrew Trevett

Kenya Medical Research Institute (KEMRI), Kisumu, Kenya

Eric Ochomo

UNICEF, 3 UN Plaza, New York, NY 10017

Timothy Grieve

\section{References}

1. Barrera R, Felix G, Acevedo V, Amador M, Rodriguez D, Rivera L, Gonzalez O, Nazario N, Ortiz M, Munoz-Jordan JL, Waterman SH, Hemme RR. Impacts of Hurricanes Irma and Maria on Ae aegypti populations, aquatic habitats, and mosquito infections with dengue, chikungunya, and zika viruses in Puerto Rico. The Am J Trop Med and Hyg. 2019; 100(6): 1413 - 1420 https://doi.org/10.4269/ajtmh.19-0015

2. Reina Ortiz M, Le NK, Sharma V, Hoare I, Quizhpe E, Teran E, Naik E, Salihu HM, Izurieta R. Postearthquake Zika virus surge: disaster and public health threat amid climatic conduciveness. Scientific Reports. 2017; 7. 10.1038/s41598-017-15706-w.

3. Hashizume M, Dewan AM, Sunahara T, Ziaur Rahman M, Yamamoto T. Hydroclimatological variability and dengue transmission in Dhaka, Bangladesh: a time-series study. BMC Infectious Diseases 2012; 12:98. https://doi.org/10.1186/1471-2334-12-98

4. CENTERS FOR DISEASE CONTROL (CDC). 2019. Zika Virus. https://www.cdc.gov/zika/index.html. Accessed 24 Jul 2019.

5. UNICEF. Review of independent evidence supporting vector control activities: prevention of diseases spread by mosquitoes. 2017; 88 pp. https://www.unicef.org/wash/files/2315-UNICEFVectorControlDisclaimer.pdf. Accessed 23 Jul 2019.

6. Bowman LR, Donegan S, McCall PJ. Is dengue vector control deficient in effectiveness or evidence? Systematic review and meta-analysis. PloS Negl Trop Dis. 2016; 10 (3): e0004551.

7. Achee NL, Gould F, Perkins TA, Reiner RC Jr, Morrison AC, Ritchie SA, Gubler DJ, Teyssou R, Scott TW. A critical assessment of vector control for dengue prevention. PloS Negl Trop Dis. 2015; 9(5): e0003655. https://doi.org/10.1371/journal.pntd.0003655

8. Horstick O, Runge-Ranzinger S. Interim analysis of the contribution of high-level evidence for dengue vector control. Southeast Asian J Trop Med and Public Health. 2015; 46, Suppl 1, 135-137. http://www.ncbi.NIm.nih.gov/pubmed/26506739.PMID:26506739. 
9. Lima E, Goulart MO, Rolim Neto ML. Meta-analysis of studies on chemical, physical and biological agents in the control of Ae aegypti. BMC Public Health. 2015; 15:858. https://doi.org/10.1186/s12889-015-2199-y PMID: 26341708.

10. World Health Organization. Zika strategic response plan, revised for July 2016 - December 2017. World Health Organization. 2016; https://apps.who.int/iris/handle/10665/246091

11. World Health Organization. Dengue guidelines for diagnosis, treatment, prevention and control: new edition. World Health Organization. 2009; https://apps.who.int/iris/handle/10665/44188

12. Andersson N, Nava-Aguilera E, Arostegui J, Morales-Perez A, Suazo-Laguna H, Legorreta-Soberanis J, Hernandez-Alvarez C, Fernandez-Salas I, Paredes-Solis S, Balmaseda A, Cortes-Guzman AJ, Serrano de los Santos R, Coloma J, Ledogar RJ, Harris E. Evidence based community mobilization for dengue prevention in Nicaragua and Mexico (Camino Verde, the Green Way): cluster randomized controlled trial. BMJ. 2015; 351: h3267 https://doi.org/10.1136/bmj.h3267

13. Loroño-Pino M, Chan-Dzul YN, Zapata-Gil R, Carrillo-Solis C, Uitz-Mena A, Garcia-Rejon JE, Keefe TJ, Beaty BJ, Eisen L. Household use of insecticide consumer products in a dengue-endemic area in Mexico. Trop Med Int Health. 2014; 19(10): 1267-1275.

14. Mulla MS, Thavara U, Tawatsin A, Kong-Ngamsuk W, Chompoosri J. Mosquito burden and impact on the poor: measures and costs for personal protection in some communities in Thailand. J Am Mosq Control Assoc. 2001; 17(3): 153-9.

15. Snehalatha KS, Ramaiah KD, Vijay Kumar KN, Das PK. The mosquito problem and type and costs of personal protection measures used in rural and urban communities in Pondicherry region, South India. Acta Trop. 2003; 88(1): 3-9.

16. Stephens C, Masamu ET, Kiama MG, Keto AJ, Kinenekejo M, Ichimori K, Lines J. Knowledge of mosquitos in relation to public and domestic control activities in the cities of Dar es Salaam and Tanga. Bull World Health Organ. 1995; 73(1): 97-104.

17. Rother HA. South African farm workers' interpretation of risk assessment data expressed as pictograms on pesticide labels. Environ Res. 2008; 108: 419-27. 10.1016/j.envres.2008.07.005.

18. Nalwanga E, Ssempebwa, JC. Knowledge and practices of in-home pesticide use: a community survey in Uganda. J Environ and Pub Health. 2011; ID 230894, 7 pages https://doi.org/10.1155/2011/230894

19. United Nations Economic Commission for Europe (UNECE). Globally Harmonized System of Classification and Labelling of Chemicals (GHS, rev.7). 2017; https://www.unece.org/trans/danger/publi/ghs/ghs_rev07/07files_e.html. Accessed 24 Jul 2019. 
20. Kenya National Bureau of Statistics (KNBS). Vol. II: Distribution of Population by Administrative Units. December 2019; 270 pp.

21. Hay SI, Rogers DJ, Shanks GD, Myers MF, Snow RW. Malaria early warning in Kenya. Trends Parasitol. 2001; 17:95-9 10.1016/S1471-4922(00)01763-3

22. Ogoma SB, Mmando AS, Swai JK, Horstmann S, Malone D, Killeen GF. A low technology emanator treated with the volatile pyrethroid transfluthrin confers long term protection against outdoor biting vectors of lymphatic filariasis, arboviruses and malaria. PLoS Negl Trop Dis. 2017; 11(4): e0005455. https://doi.org/10.1371/journal.pntd.0005455

23. McPhatter LP, Mischler PD, Webb MZ, Chauhan K, Lindroth EJ, Richardson AG, Debboun M. Laboratory and semi-field evaluations of two (transfluthrin) spatial repellent devices against $\mathrm{Ae}$ aegypti. US Army Med. Dep. J. 2017; 13-22.

24. Mmbando AS, Ngowo H, Limwagu A, Kilalangongono M, Kifungo K, Okumu FO. Eave ribbons treated with the spatial repellent, transfluthrin, can effectively protect against indoor-biting and outdoorbiting malaria mosquitoes. Malar. J. 2018; 17: 368. https://doi.org/10.1186/s12936-018-2520-1

25. Syafruddin D, Asih PBS, Rozi IE, Permana DH, Nur Hidayati AP, Syahrani L, Zubaidah S, Sidik D, Bangs MJ, Bøgh C, Liu F, Eugenio EC, Hendrickson J, Burton T, Baird JK, Collins F, Grieco JP, Lobo NF, Achee NL. Efficacy of a Spatial Repellent for Control of Malaria in Indonesia: A Cluster-Randomized Controlled Trial. Am J Trop Med Hyg. 2020 Jul;103(1):344-358. doi: 10.4269/ajtmh.19-0554. Epub 2020 May 14. Erratum in: Am J Trop Med Hyg. 2020 Nov;103(5):2151. PMID: 32431275; PMCID: PMC7356406.

26. Ogoma SB, Moore SJ, Maia MF. A systematic review of mosquito coils and passive emanators: defining recommendations for spatial repellency testing methodologies. Parasites \& Vectors 2012; 5:287. https://doi.org/10.1186/1756-3305-5-287

27. Avicor SW, Owusu EO, Wajidi MF. D-allethrin based mosquito coils for mosquito control: knockdown and mortality effects on the malaria vector An gambiae sensu lato. Int. J. Agric. Biol. 2013; 15: 1035-1038.

28. Khadri MS, Kwok KL, Noor MI, Lee HL. Efficacy of commercial household insecticide aerosol sprays against Ae aegypti under simulated field conditions. Southeast Asian J. Trop. Med. Pub Health. 2009; 1226-34.

29. Kuri-Morales P, Correa-Morales F, González-Acosta C, Moreno-Garcia M, Davalos-Becerril E, BenitezAlva JI, Peralta-Rodriguez J, Salazar-Bueyes V, Gonzalez-Roldan JF. Efficacy of 13 commercial household aerosol insecticides against Ae aegypti (Diptera: Culicidae) from Morelos, Mexico. J Med Ent. 2018; 55 (2): 417-422, https://doi.org/10.1093/jme/tjx212 
30. Makworo NK, Ochieng VO, Ogoyi DO, Mukabana RW. Knock down efficacy of commercially available insecticides against An. gambiae. J App Biol Biotech. 2017; 5 (02): 077-084.

31. World Health Organization. Report of the thirteenth WHOPES working group meeting: Review of Olyset LN, Dawaplus 2.0 LN, Tianjin Yorkool LN. 2009.

https://apps.who.int/iris/bitstream/handle/10665/44212/9789241598712_eng.pdf. Accessed 24 Jul 2019.

32. Karch S, Asidi N, Manzambi Z, Salaun JJ, Mouchet J. Impact of deltamethrin-impregnated bednets on biting rates of mosquitoes in Zaire. J Am Mosq Control Assoc. 1995; 11(2):191-194.

33. Loroño-Pino M, Uitz-Mena A, Carrillo-Solís CM, Zapata-Gil RJ, Camas-Tec DM, Talavera-Aguilar LG, Cetina-Trejo RC, Flores-Flores LF, Puc-Tinal MC, Caamal-Jimenez C, Reyes-Solis G, Garcia-Rejon JE, Saavedra-Rodriguez K, Eisen L, Keefe TJ, Black WC, Beaty BJ. The use of insecticide-treated curtains for control of Ae aegypti and dengue virus transmission in "Fraccionamiento" style houses in México, J Trop Med. 2018; Article ID 4054501, 22 pages, https://doi.org/10.1155/2018/4054501.

34. Pérez D, Van der Stuyft P, Toledo ME, Ceballos E, Fabre' F, Lefèvre P. 2018. Insecticide treated curtains and residual insecticide treatment to control Ae aegypti: an acceptability study in Santiago de Cuba. PLoS Negl Trop Dis. 2018; 12(1): e0006115. https://doi.org/10.1371/journal. pntd.0006115

35. World Health Organization. 2018; https://www.who.int/pq-vector-control/prequalifiedlists/LetterFinalDecisionDocumentAquatain.pdf?ua=1. Accessed 23 Jul 2019.

36. Mbare O, Lindsay S, Fillinger U. Aquatain $®$ Mosquito Formulation (AMF) for the control of immature An. gambiae sensu stricto and An. arabiensis: dose-responses, persistence and sub-lethal effects. Parasites \& Vectors. 2014; 7:438. https://doi.org/10.1186/1756-3305-7-438

37. Bukhari T, Takken W, Githeko AK, Koenraadt CJM. Efficacy of Aquatain, a Monomolecular Film, for the control of malaria vectors in rice paddies. PloS ONE. 2011; 6(6): e21713. https://doi.org/10.1371/journal.pone.0021713

38. Ngrenngarmlert W, Sukkanon C, Yaicharoen R, Chareonviriyaphap T. Physical influence on larvicidal and pupicidal activity of the silicone-based monomolecular film. Acta Trop. 2016; 162: 239-244.

39. Temba V, Lyaruu LJ, Mahande AM, Kweka EJ. Bio-efficacy of Tabard® Spray and Tabard® Lotion against malaria vectors in laboratory and in the field conditions. J Transm Dis Immun. 2017; 1(2):16. https://doi.org/10.21767/2573-0320.100016

40. Durrheim DN, Govere J. Malaria outbreak control in an African village by community application of 'deet' mosquito repellent to ankles and feet. Med. Vet. Entomol. 2002; 16: 112-115.

41. Govere J, Braack LEO, Durrheim DN, Hunt RH, Coetzee M. Repellent effects on An arabiensis biting humans in Kruger Park, South Africa. Med. Vet. Entomol. 2001; 15: 287-292. 
42. Badolo A, Ilboudo-Sanogo E, Ouedraogo AP, Costantini C. Evaluation of the sensitivity of Ae aegypti and An gambiae complex mosquitoes to two insect repellents: DEET and KBR 3023. Trop. Med. Int. Heal. 2004; 9: 330-334.

43. Bhatt S, Weiss DJ, Cameron E, Bisanzio D, Mappin B, Dalrymple U, Battle K, Moyes CL, Henry A, Eckhoff PA, Wenger EA, Briet O, Penny MA, Smith TA, Bennett A, Yukich J, Eisele TP, Griffin JT, Fergus CA, Lynch M, Lindgren F, Cohen JM, Murray CLJ, Smith DL, Hay SI, Cibulskis RE, GethingPW. The effect of malaria control on Plasmodium falciparum in Africa between 2000 and 2015. Nature. 2015; 526(7572): 207-211. https://doi.org/10.1038/nature15535

44. Hemingway J, Ranson H, Magill A, Kolaczinski J, Fornadel C, Gimnig J, Coetzee M, Simard F, Roch DK, Hinzoumbe CK, Pickett J. Averting a malaria disaster: will insecticide resistance derail malaria control? Lancet 2016; 387: 1785-1788. https://doi.org/10.1016/S0140-6736

45. World Health Organization. Technical handbook for dengue surveillance, dengue outbreak prediction/detection and outbreak response ("model contingency plan"). 2016; 92pp. https://www.who.int/tdr/publications/year/2016/tech_handbook_dengue/en/ISBN 978924154973 8

46. Roiz D, Wilson AL, Scott TW, Fonseca DM, Jourdain F, Muller P, Velayudhan R, Corbel V. Integrated Aedes management for the control of Aedes-borne diseases. PLoS Negl Trop Dis 2018; 12(12): e0006845. https://doi.org/10.1371/journal.pntd.0006845

47. Heydari N, Larsen DA, Neira M, Ayala EB, Fernandez P, Adrian J, Rochford R, Stewart-lbarra AM. Household dengue prevention interventions, expenditures, and barriers to Ae aegypti control in Machala, Ecuador. Int J Environ Res Public Health. 2017; 14(2):196.

https://doi.org/10.3390/ijerph14020196

48. ACAPS (Assessment Capacities Project). Kenya drought. 2019; https://www.acaps.org/sites/acaps/files/products/files/20190604_start_acaps_kenya_drought.pdf. Accessed 23 Jul 2019.

49. UNICEF. Rapid Response Teams: A UNICEF experience. 2019; 4pp. https://www.unicef.org/media/73126/file/Rapid-Response-Teams-A-UNICEF-Experience.pdf. Accessed 24 May 2021.

50. Sirleaf E, Clark H. Report of the Independent Panel for Pandemic Preparedness and Response: making COVID-19 the last pandemic. Lancet 2021; https://doi.org/10.1016/S0140-6736(21)01095-3. Accessed 24 May 2021.

51. Morrison A, Reiner Jr R, Elson W, Astete H, Guevara C, del Aguila C, Bazan I, Siles C, Barrera P, Kawieckim A, Barker C, Vasquez G, Escobedo-Vargas K, Flores-Mendoza C, Huaman A, Leguia M, Silva M, Jenkins S, Campbell W, Abente E, Hontz R, Paz-Soldan V, Grieco J, Lobo N, Scott T, Achee N. 
Efficacy of a Spatial Repellent for Control of Aedes-Borne Virus Transmission: A Cluster Randomized Trial in Iquitos, Peru. 2021. medRxiv 2021.03.03.21252148; doi:

https://doi.org/10.1101/2021.03.03.21252148. Accessed 24 May 2021.

52. Oria P, Moshi V, Odero J, Ekodir S, Monroe A, Harvey S, Ochomo E, Black D. A retail audit of mosquito control products in Busia County, western Kenya. Malaria J. 2021. 20(163).

https://doi.org/10.1186/s12936-021-03695-1. Accessed 24 May 2021.

\section{Figures}

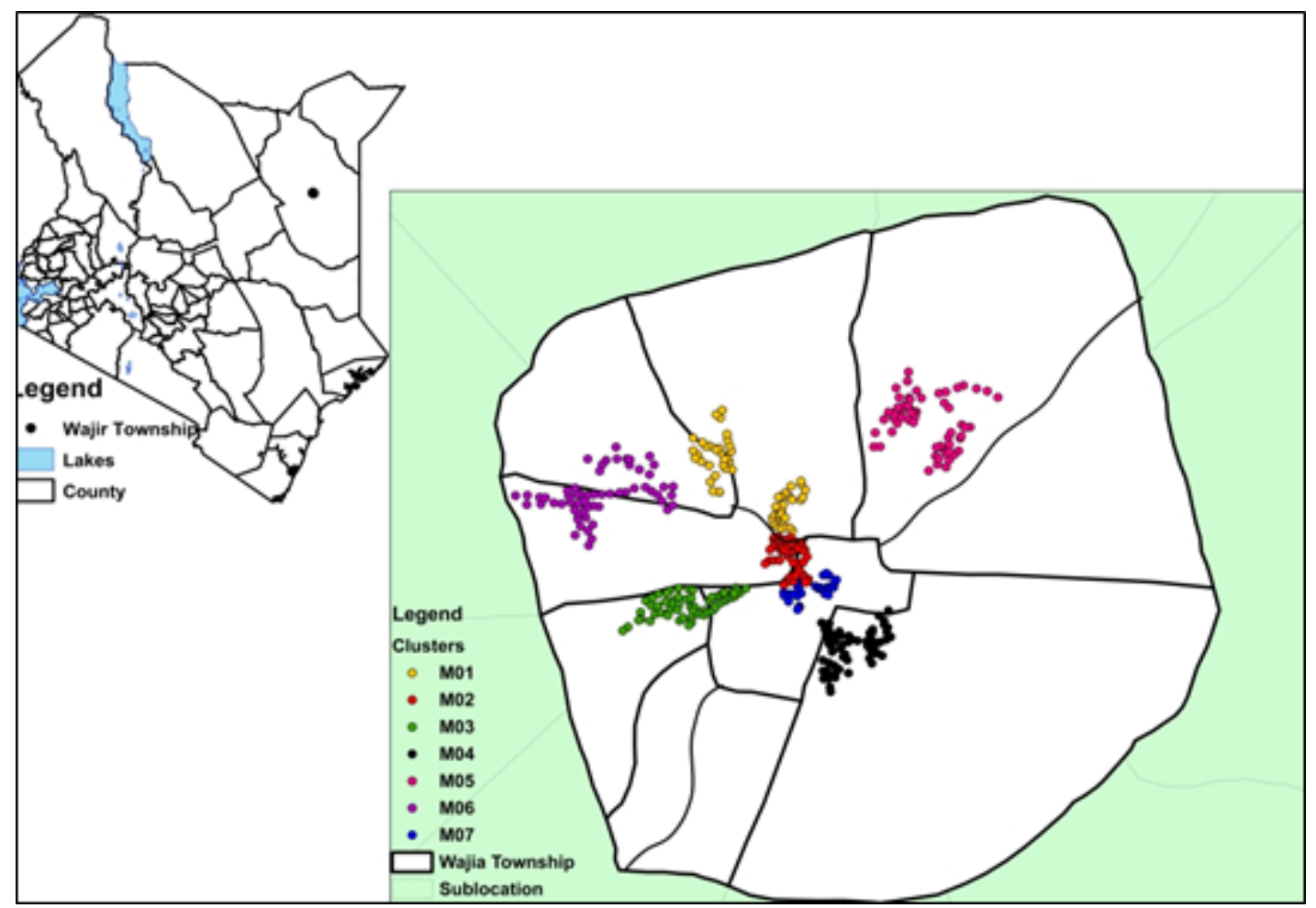

Figure 1

Location of treatment neighborhoods across Wajir in Kenya 

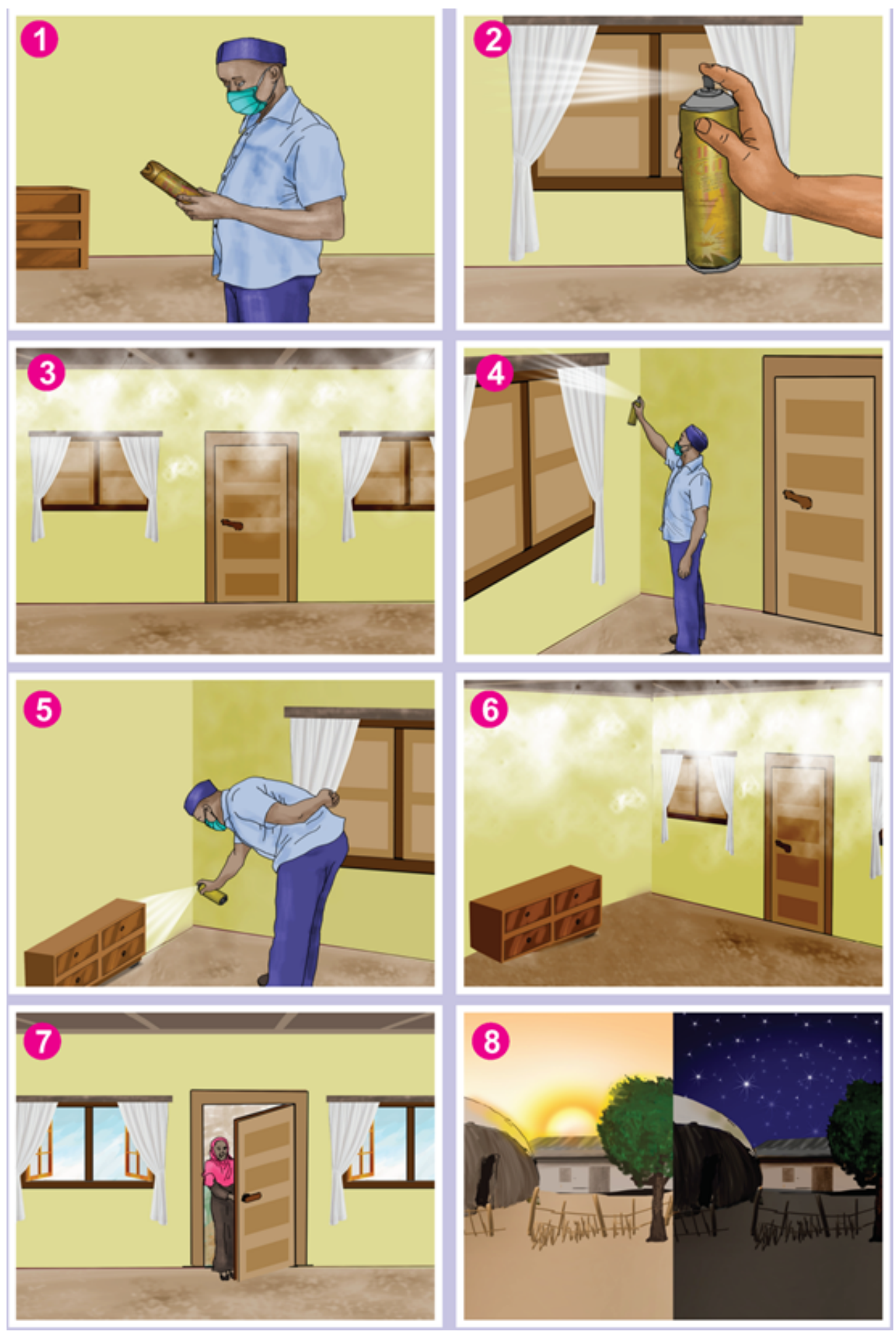

Figure 2

Pictogram Directions for Use (DFU) for aerosol insecticide sprayer application (developed/copyright by The MENTOR Initiative) 


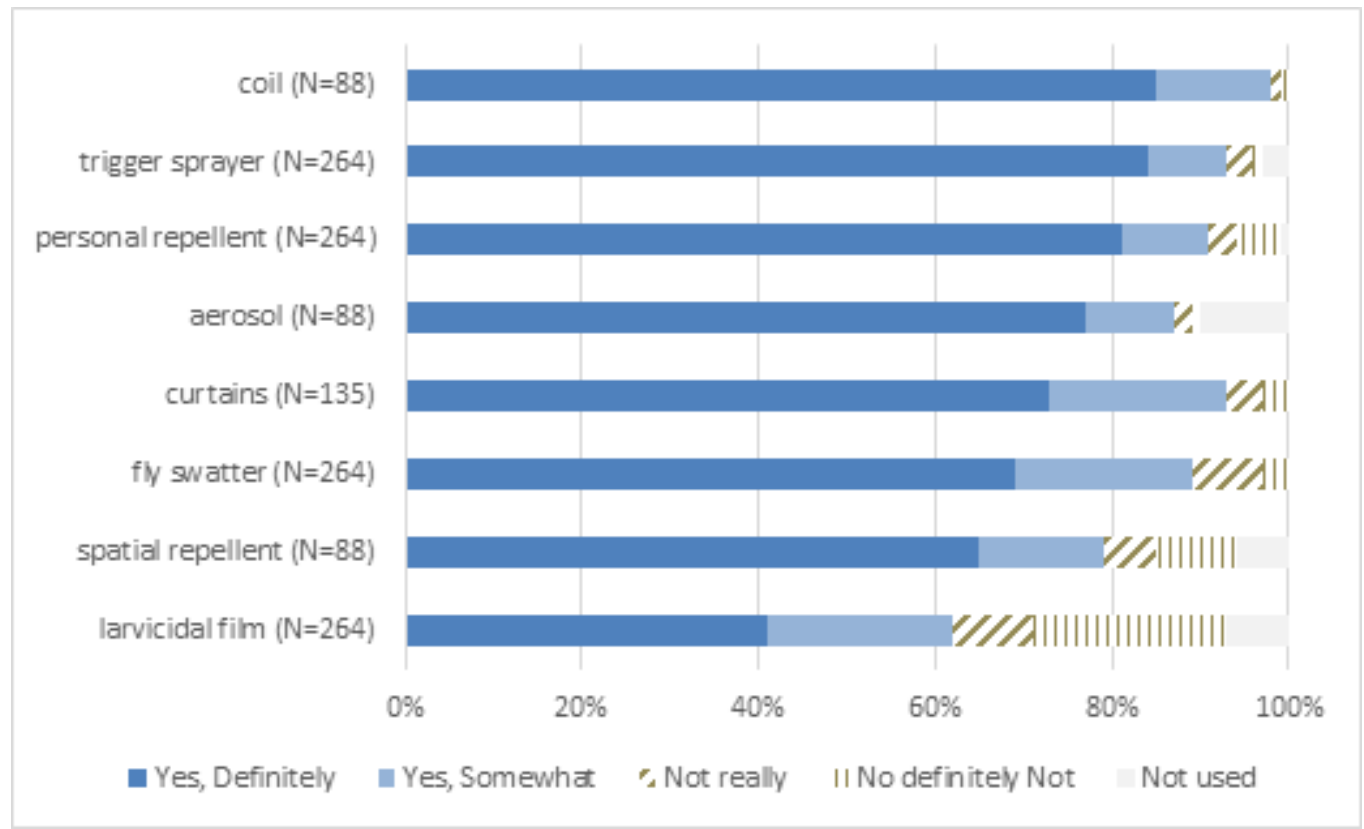

\section{Figure 3}

Participant (\%) understanding of the purpose of products included in the family vector control response kit. The kits were configured with different ingredients with all (264) having trigger sprayers, personal repellent, larvicidal film, and fly swatters. Half (135) included insecticide treated curtains and each third of the kits included either mosquito coils (88), insecticide aerosols (88), or spatial repellent plastic sheets (88).

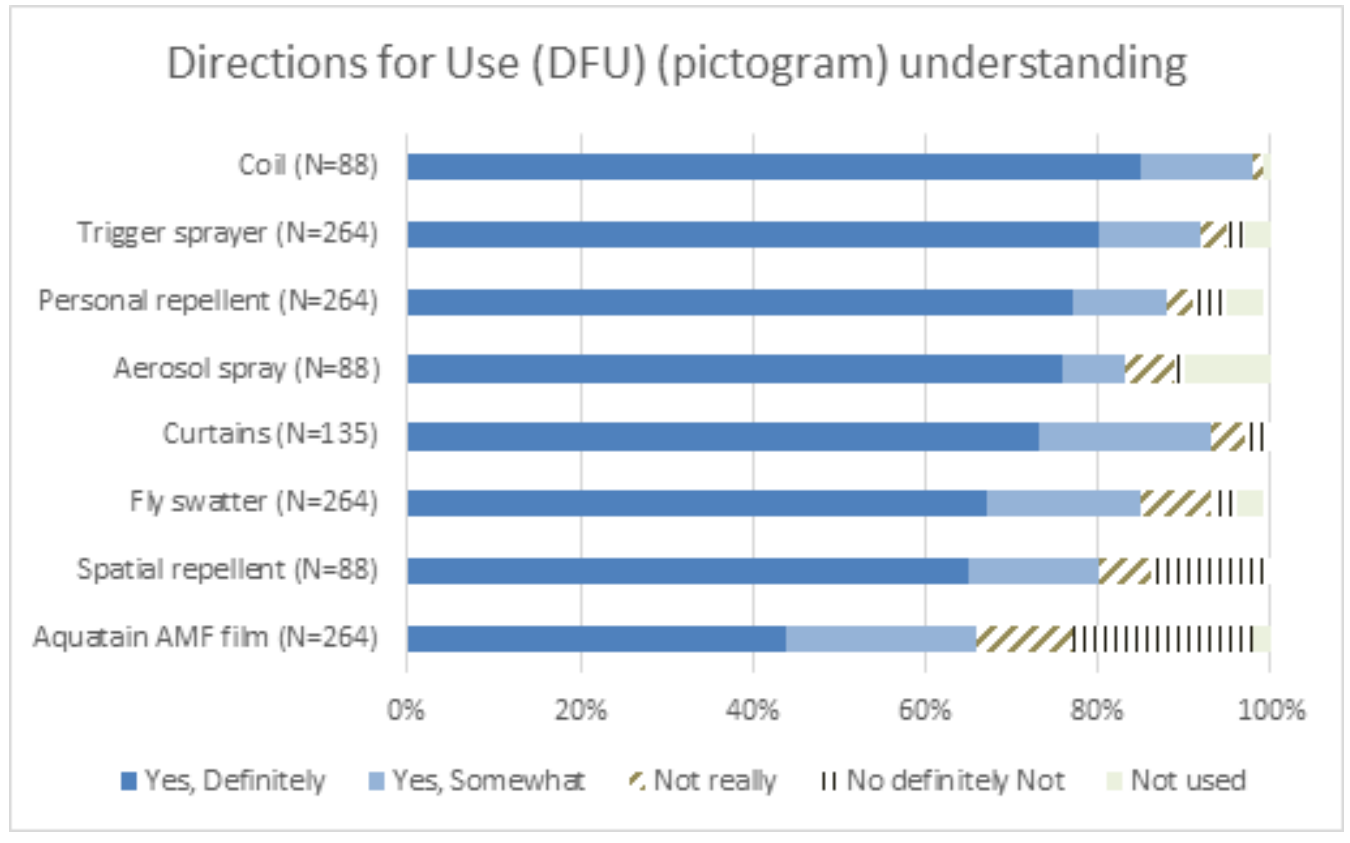

\section{Figure 4}

Interviewed participants (\%) understanding of the pictogram Directions for Use (DFU) for each product in their kits. 


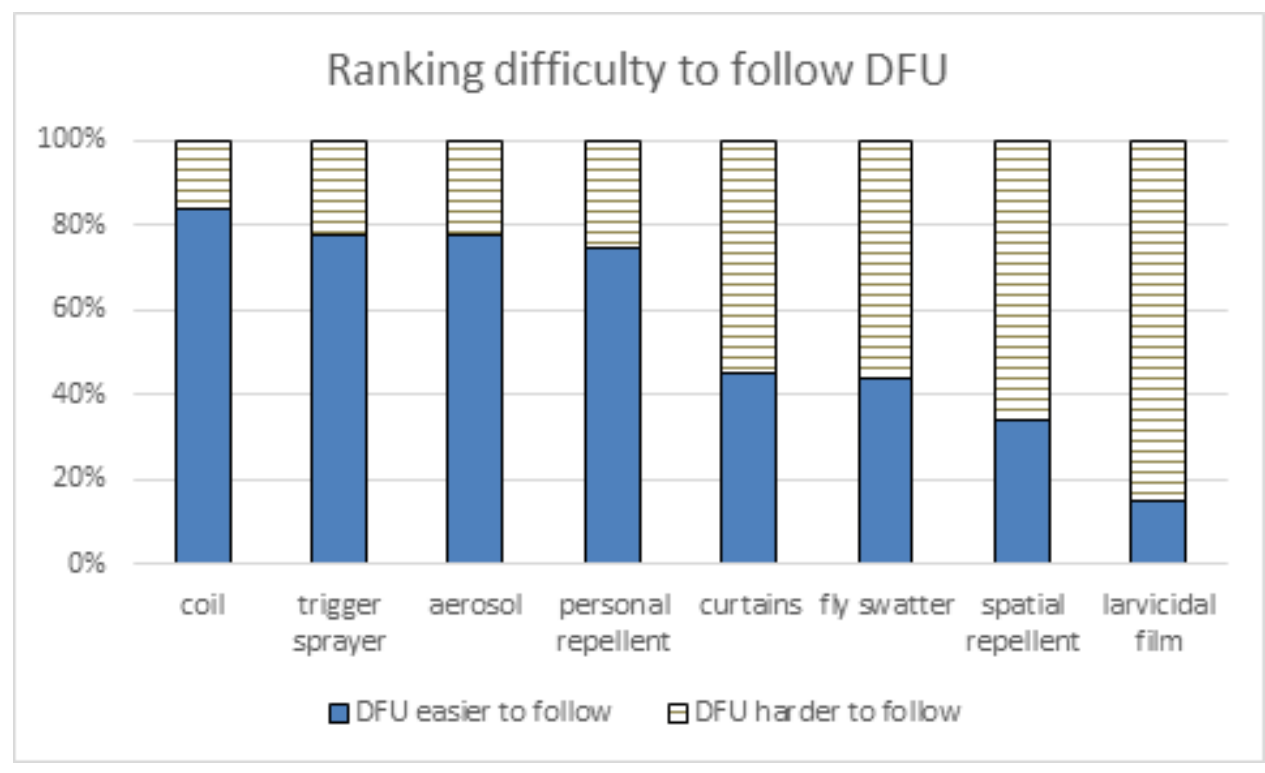

Figure 5

Participants interviewed (\%) who ranked product Directions for Use (DFU) easier or harder to follow.

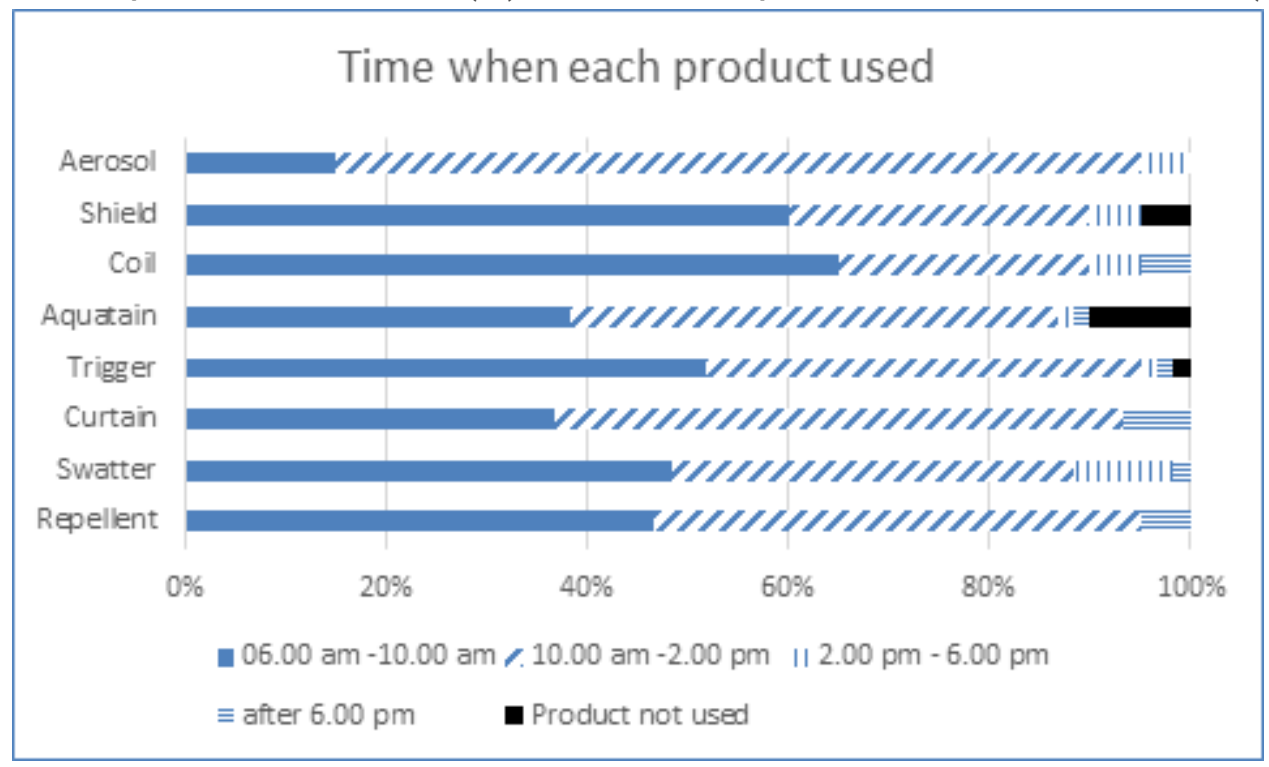

\section{Figure 6}

Time of day when respondents, on average, thought mosquito control products should be used. 


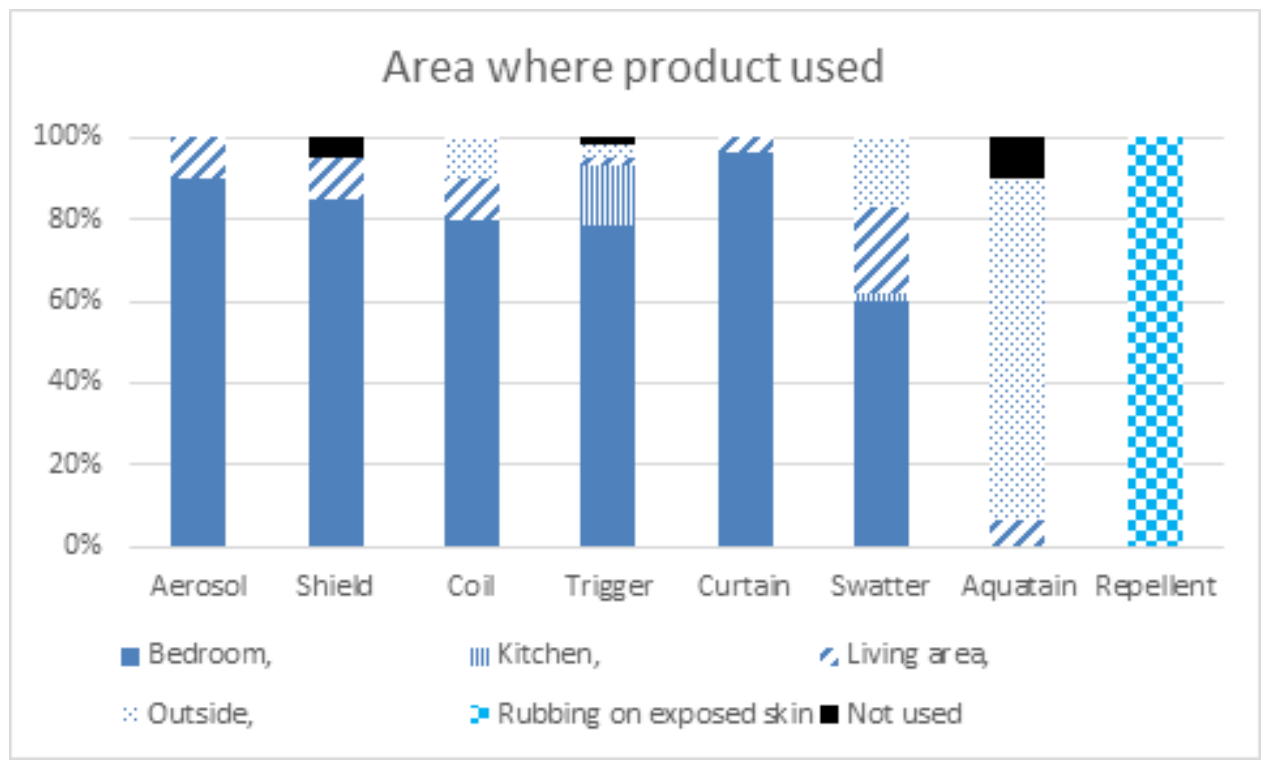

Figure 7

Household locations where products were used, as identified by interviewed participants (\%).

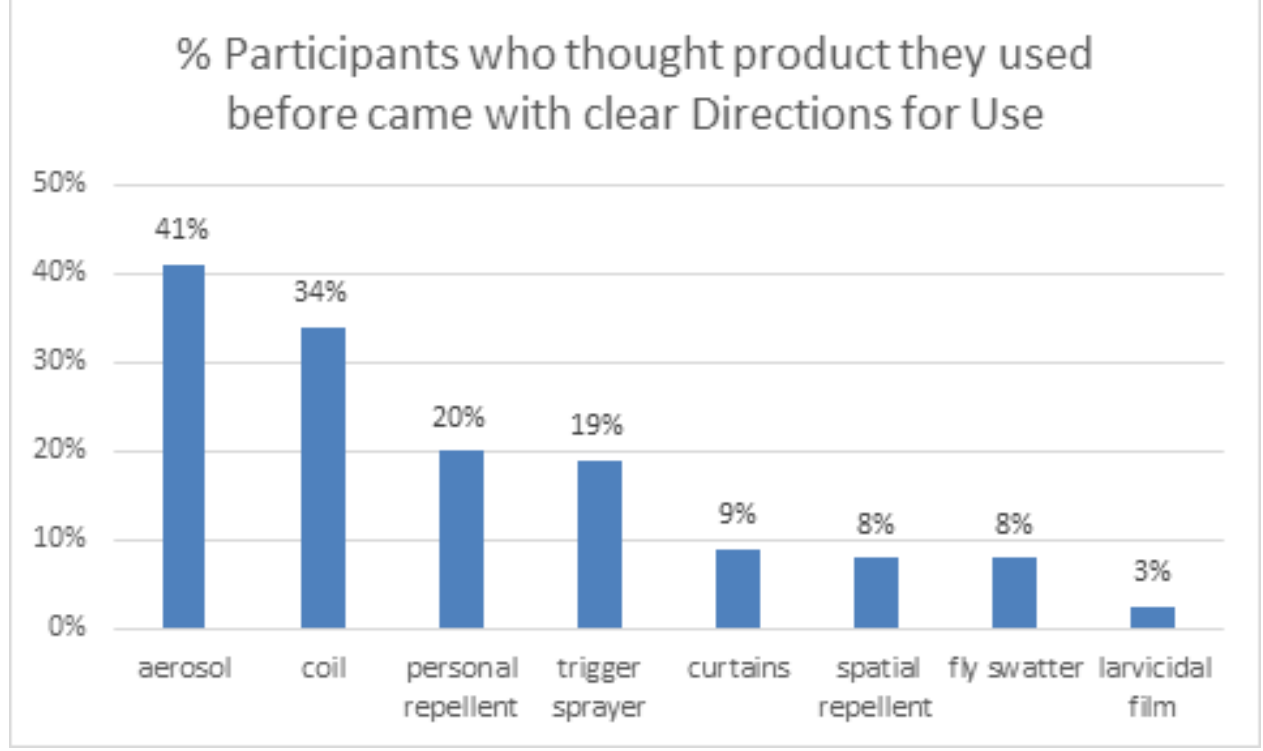

Figure 8

Participants (\%) who thought products they used before the study came with clear Directions for Use (DFU). 


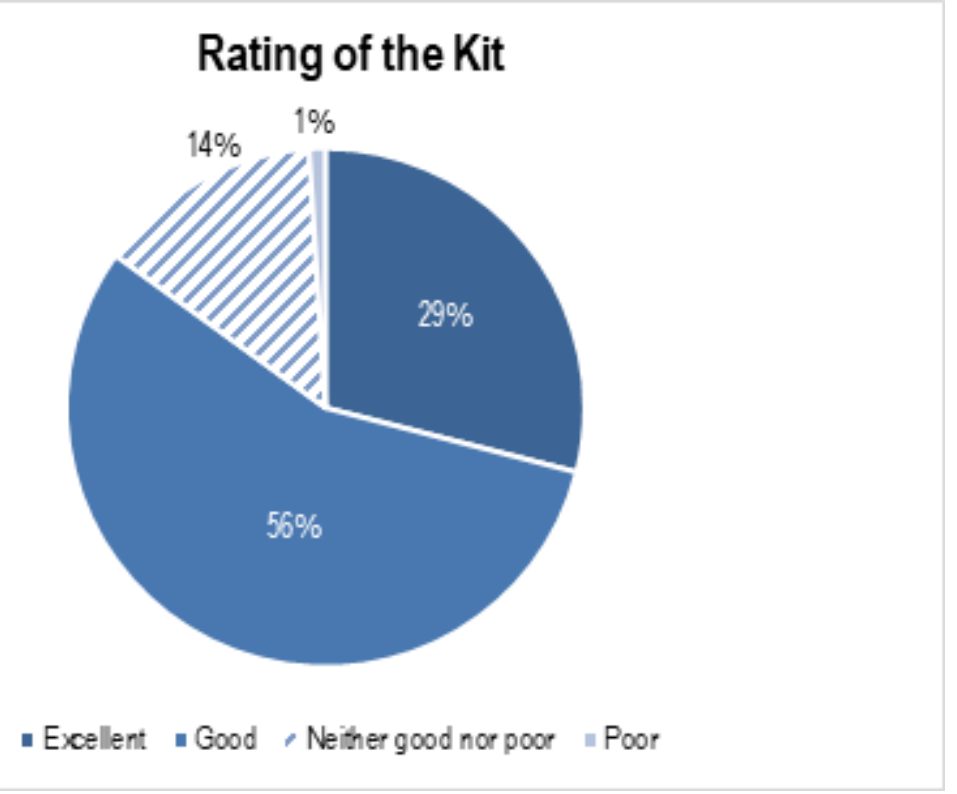

Figure 9

Rating by participants $(\mathrm{N}=264)$ of the value of the family vector control response kit

\section{Supplementary Files}

This is a list of supplementary files associated with this preprint. Click to download.

- GA.png 